\title{
FRED S. KELLER, UM REFORÇADOR CONDICIONADO GENERALIZADO
}

\section{FRED S. KELLER: A GENERALIZED CONDITIONED REINFORCER ${ }^{I}$}

\author{
MURRAY SiDMAN \\ SARASOTA, FLORIDA, USA
}

\begin{abstract}
RESUMO
Este tributo a Fred S. Keller descreve como ele dedicou sua carreira a aplicar conhecimento científico sobre o comportamento para o avanço da educação. Em seus últimos anos ele externou seu desapontamento com o fracasso da aplicação de forma generalizada em universidades e no sistema escolar de seu Sistema Personalizado de Instrução, e apontou as razôes porque a educação permaneceu intocada por aplicações da ciência do comportamento. Ele reconheceu que a ciência deve ir além do comportamento individual e deve procurar um entendimento do comportamento na cultura, acrescentando, a suas técnicas remediativas bem sucedidas, procedimentos que ampliem seu alcance a populações como um todo.

Palavras-chave: Fred Keller, Sistema Personalizado de Instrução, PSI, aplicações da ciência do comportamento, educação
\end{abstract}

\section{ABSTRACT}

This tribute to Fred S. Keller describes how he dedicated his career to applying scientific knowledge about behavior to the improvement of education. In his later years he acknowledged his disappointment at the failure of his Personalized System of Instruction to be generally applied in universities and in school systems, and pointed out reasons why education has remained untouched by applications of the science of behavior. He realized that science must go beyond the study of individual behavior and must seek an understanding of behavior in whole cultures, adding to its many successful remedial techniques procedures that extend in scope to total populations.

Key words: Fred Keller, Personalized System of Instruction, PSI, applications of the science of behavior, education

Em ocasiōes como esta, os conferencistas convidados são geralmente solicitados a submeter títulos e resumos de conferências que eles ainda não prepararam. Minha estratégia, em ocasiões assim, é inventar algo tão geral que possa abranger qualquer coisa que eu venha, por fim, decidir a falar. Isso foi o que fiz nesta ocasião. O que eu poderia dizer sobre Fred Keller, em uma frase, que fosse apropriado para o que quer que eu pudesse vir a falar sobre ele em minha apresentação?

Acho que a maioria concordaria que fui bem sucedido. Reforçadores condicionados generalizados são bons; nós os amamos, como amávamos Fred Keller. A maioria de nós aqui, e muitos outros que não puderam estar aqui hoje, somos a sua família estendida.
No entanto, reforçadores condicionados generalizados são complexos; com freqüência nós não os entendemos tão completamente quanto gostaríamos e freqüentemente não avaliamos tudo o que eles têm a nos oferecer. Por exemplo, eu tenho certeza de que muitos de vocês se lembram quando Marian e Keller Breland (Breland \& Breland, 1961) ensinaram porcos a trocar fichas por comida, mas então os porcos começaram a mastigar as fichas ao invés de trocá-las. Os animais não apenas tratavam as fichas como comida, mas pareciam preferilas; mastigar as fichas os impedia de obter comida de verdade. Terá sido essa uma demonstração precoce de uma conseqüência da equivalência de estímulos no mundo real?

\footnotetext{
1 “The Fred Keller Lecture”, 19 de março de 2006, Eastern Psychological Association, Baltimore (MD, EUA). Texto publicado simultaneamente em inglês, em The Behavior Analyst, 29 (2), 235-242 (2006). Solicitação de separatas para murraysidman@comcast.net. Tradução: Olavo de Faria Galvão, Universidade Federal do Pará, Brasil.
} 
Posteriormente, Karen Pryor relatou que, conduzindo treino com um sinalizador (clicker training), primeiro com cães (Pryor, 1989) e depois com crianças (Pryor, comunicação pessoal), seus estudantes, tanto os cães quanto as crianças, também tentaram pegar os sinalizadores. É como se eles preferissem os sinalizadores aos reforçadores que os sinalizadores anunciavam.

E agora, nós nos vemos amando Fred Keller mais do que quaisquer dos reforçadores que ele tornou possíveis para nós. Todos esses quebra-cabeças sobre reforçamento condicionado generalizado sugerem pesquisa que ainda permanece por ser feita.

Porque reforçamento condicionado generalizado, então, não diz tudo o que gostaríamos de dizer sobre Fred, eu gostaria de descrever algumas das características dele que poderiam nos ajudar a apreciá-lo ainda mais do que já o fazemos e, adicionalmente, poderiam nos ajudar a entendê-lo não apenas como um cientista e professor, mas como um homem. Nós tendemos freqüentemente a esquecer que nossos mais prezados cientistas, professores e profissionais-modelo, são também homens e mulheres, pessoas que fazem o que fazem por razões que são humanas e gerais. Eu sempre digo que a primeira obrigação de todos os comportamentalistas é obedecer às leis do comportamento; se não o fazem, como podem esperar que outros acreditem em suas afirmaçōes de que o comportamento é determinado, que o comportamento de todos os organismos, inclusive o dos professores, cientistas e profissionais-modelo, está sujeito às mesmas leis?

Infelizmente, alguns analistas do comportamento parecem sentir que, porque conhecem e entendem as leis do comportamento, eles estão isentos dessas leis.
Cientistas cumprem com suas tarefas comportando-se; professores influenciam seus estudantes comportando-se. Se nós os erigimos como nossos modelos, podemos aumentar sua efetividade em influenciar nosso comportamento olhando mais de perto para o que influenciou o deles.

Fred S. Keller foi, de muitas maneiras, um homem notável. Uma das coisas mais notáveis sobre ele, era que ele nunca se considerava notável. Eu sei, por interações pessoais com ele, que, em seus últimos anos ele ficava genuinamente confuso sobre porque as pessoas continuavam pedindo-lhe para fazer palestras em encontros profissionais. $\mathrm{Na}$ verdade, em suas últimas palestras, ele não enfatizou suas muitas realizações e sucessos, antes expressou seu desapontamento com o fato de seu Sistema de Instrução Personalizado não ter sido amplamente adotado. Por exemplo, em uma palestra convidada em 1982 para a Divisão 2 da American Psychological Association (Keller, 1985), ele disse o seguinte:

Quando o Professor Brewer pediu-me para falar a vocês, eu disse-lhe que já havia feito isso, há 15 anos atrás... e que eu não tinha tido nenhuma idéia nova desde então. Isso não pareceu dissuadi-lo. "Você vai pensar alguma coisa, tenho certeza," ele disse. Então eu estou aqui hoje para provar a vocês que eu estava certo. (Keller, 1985, p. 4).

Em outras palavras, ele ia provar que não tinha tido uma idéia nova por quinze anos e que ele iria, não obstante, pensar em algo para dizer. Quantos de nós estivemos na mesma situação, mas não tivemos coragem de admitir?

Então, ele prosseguiu com umas poucas palavras sobre a origem do PSI, e sobre o assunto de sua palestra. Para citá-lo novamente: 
Em 1967, eu estava irrompendo com uma grande idéia. Essa idéia tinha ocorrido a mim e a três companheiros de repente, como a faísca de um raio. Dizem que grandes idéias freqüentemente ocorrem dessa maneira. Então eu falei sobre educação - mais especificamente, instrução. Eu descrevi um modo de ensinar que é conhecido por alguns de vocês como PSI - um sistema personalizado de instrução. Hoje eu vou discutir uma nova descoberta que eu fiz. Esta é baseada em pesquisa, ao invés de em intuição. Ela derivou de entrevistas com muitos professores em todos os Estados Unidos, que cuidadosamente me explicaram porque eles foram incapazes de ensinar com o PSI. Usando o método indutivo, eu cheguei à conclusão de que o PSI, ao invés de ser uma faísca de raio, era meramente uma chama na panela. (Keller, 1985, p. 4).

Não é difícil de detectar um sinal de amargura aqui. Nesse tom, ele prosseguiu relatando os resultados de entrevistas de pesquisa que ele simulou ter feito com muitos professores anônimos, e de pesquisa bibliográfica que trouxe à luz revelaçôes feitas por pessoas famosas de outras disciplinas que fizeram freqüentemente pronunciamentos sobre educação, ensino e aprendizagem.

Primeiro, disseram-lhe que um sistema ideal de ensino tem que ser seletivo, ele deve separar os estudantes-ovelha dos estudantescabra. Segundo, ele aprendeu que o sistema deve cultivar a competição entre os estudantes - assegurando a sobrevivência do mais apto. Terceiro, os métodos ideais de ensino devem ser relevantes para a vida diária; eles não devem mimar os estudantes com atenção individual, mas devem prepará-los para o mundo onde cobra engole cobra, que os espera fora da escola - eles devem aprender a se defender por si próprios e lidar com a competição. Quarto, todos os estudantes devem ter oportunidades iguais de sucesso, de maneira que o insucesso daqueles com bases insuficientes ou QI baixo não possa ser atribuído ao professor. Quinto, o sistema ideal não deve ser muito dispendioso, ainda que - sexto - os professores devam achálo financeiramente recompensador. De outra maneira, jamais poderíamos atrair grandes professores. Sétimo, o sistema ideal deve ser ordenado e regular, com os estudantes, sejam cordeiros ou cabras, sendo treinados para serem pontuais, mantenedores de seus compromissos, assim como no mundo fora $\mathrm{da}$ escola para o qual sua educação deveria preparálos. E finalmente, ainda que uns poucos professores tenham sugerido que um sistema ideal deveria garantir o domínio de cada matéria ensinada, outros entrevistados, ele disse, levaram Keller a descartar essa noção como absurda, como se segue:

Você realmente quer que seus alunos se lembrem de tudo que você lhes diz? As coisas que você diz podem viver para assombrar você. Além do mais, se todo estudante aprendesse tudo, então para você todos os estudantes iriam ser parecidos você não poderia distinguir os brilhantes dos burros. Além disso, você não poderia dizer sempre se alguma matéria foi ou não aprendida. $\mathrm{O}$ estudante pode ter atingido os requisitos cognitivos, mas pode não expressá-los em comportamento. Eles podem ser guardados na memória, de onde não podem ser recuperados ou podemos ter falhado em ativar o núcleo adequado no hemisfério apropriado. (Keller, 1985, p. 5).

Assim sendo, com Keller, nós devemos riscar o domínio da matéria da lista de características do sistema ideal de instrução. 
Com base nessas revelações de seus dados de pesquisa, Keller continuou perguntando se o sistema ideal existe. Ele concluiu que nós o temos bem aqui conosco, na forma do GSI, o Sistema Grupal de Instrução.

O Sistema de Ensino Ideal:

GSI, O Sistema de Instrução em Grupo

1) Seletividade; 2) Competição; 3) Relevância; 4) Justiça; 5) Economia; 6) Recompensador para o Professor; 7) Regularidade; e 8) Domínio - Desnecessário.

Instrução grupal por preleção (palestras) provê todos os requisitos do sistema ideal seletividade, competição, relevância, justiça, economia, recompensa para o professor e regularidade. De suas entrevistas e pesquisa bibliográfica, Keller relata ter aprendido que ensinar é uma arte, não uma ciência, e que os melhores professores são conhecedores, preparados, divertidos e dramáticos. Professores são artistas e ensinar não pode ser feito por fórmula. Um comentarista, que realmente apreciara os sucessos do PSI, concluiu, no entanto, que ele era muito dispendioso. Aumentar os impostos para melhorar a educação seria imoral; ninguém tem o direito de pedir isso à sua comunidade. Em uma nota mais otimista, um eminente cientista estava certo de que as tecnologias do DNA poderiam em breve permitir-nos planejar estratégias educacionais individuais, incluindo a produção de professores ideais.

Tendo examinado muitas fontes além das que eu destaquei rapidamente, Keller concluiu assim:

Há quinze anos, eu acreditei no PSI. Eu pensava que era um sistema ideal e fiz meu melhor para espalhá-lo mundo afora. ... Mas eu estava vivendo um sonho. Agora posso perceber o seguinte: $\mathrm{O}$ sistema era irrealista e envolvia gente demais; era muito caro, e possivelmente imoral; e, em última análise, era desnecessário. Alguns professores bem selecionados e alguns estudantes bem selecionados podem prover tudo o que precisamos na educação superior. O que realmente precisamos hoje é a separação precoce de ovelhas e cabras, juntamente com as estratégias da genética molecular (Keller, 1985, p. 8).

Fred S. Keller era claramente ambicioso, queria deixar sua marca no mundo, e ele tinha tido considerável sucesso em fazêlo, em muitas áreas. Por exemplo, seu apoio experimental, teórico e promocional ao trabalho de B. F. Skinner trouxe-lhe uma abundância de reforçadores profissionais e pessoais; ele foi uma vez presidente desta própria organização, a Eastern Psychological Association. Em um estágio inicial de desenvolvimento do campo, 90 por cento daqueles que trabalhavam com condicionamento operante eram ou estudantes de Keller ou eram aqueles, como Schoenfeld, a quem ele tinha indicado essa direção. Seu trabalho pioneiro sobre comportamento de fuga (Keller, 1941), usando uma técnica que fez uso de aversão à luz no rato de laboratório, foi um bem reconhecido precursor de desenvolvimentos posteriores, experimentais, teóricos e aplicados no campo do comportamento controlado por eventos aversivos. Adicionalmente, ao fazer aquela pesquisa ele nos ensinou a importância de olhar os sujeitos e não apenas registrar números. Assim foi que ele aprendeu que alguns animais que pareciam incapazes de apagar uma luz brilhante pressionando uma barra ou saltando por sobre uma barreira tinham, na realidade, produzido suas próprias soluções para o problema; eles simplesmente fechavam os olhos e escondiam suas cabeças sob as patas dianteiras cruzadas. Hoje, analistas do 
comportamento fazem grande uso dessa observação em situações de aplicação, provavelmente sem sequer conhecer sua história, ao conduzirem o que é conhecido como análise funcional, por meio da qual se faz testes para determinar os reais reforçadores para o que parece ser, na superfície, comportamento não adaptativo.

O curso introdutório baseado em laboratório de Keller e Schoenfeld na Columbia University (Keller \& Schoenfeld, 1949) deu à Psicologia nova estatura entre as ciências - por causa dessa estatura, meu título concedido pela Columbia University não foi em Psicologia; foi um Ph.D. em Ciência Pura. Professores prestigiados e poderosos nos Departamentos de Humanidades não acharam agradável essa concepção de Psicologia, e suas pressões acabaram por tornar pessoalmente não recompensador para Keller e Schoenfeld permanecer em Columbia, mas a semente que eles plantaram havia se espalhado. Como um resto remanescente daquele conflito, nós vemos a psicologia Freudiana florescendo hoje não em departamentos de Psicologia ou mesmo de Psiquiatria, mas em departamentos de literatura e artes.

A adoção pelas nossas forças armadas de seu método código-voz (Keller, 1943) para ensinar o código Morse durante a Segunda Guerra Mundial foi uma impressionante aplicação bem sucedida de princípios básicos de análise do comportamento. Os jovens homens e mulheres que receberam esse treinamento vieram, em muito pouco tempo, a participar efetivamente de nossas operações de inteligência militar. Eu sei disso pessoalmente, porque fui um daqueles que recebeu aquele treinamento e, então, fui trabalhar na interceptação de mensagens de rádio do exército Japonês - interceptaçôes que tiveram alguns resultados espetaculares.
Juntamente com Paul Wilson, a introdução, por Keller, do esquema de reforçamento diferencial de taxas baixas (differential-reinforcement-of-low-rate - DRL, Wilson \& Keller, 1953) introduziu uma técnica que trabalhadores de laboratório e trabalhadores aplicados ainda consideram útil. Da avaliação dos efeitos comportamentais de novas drogas, à diminuição de comportamento mal adaptativo que ocorre freqüentemente, ao estudo de discriminação temporal (timing), o esquema DRL continua consistentemente efetivo.

E finalmente, seus muitos estudantes, que aprenderam com ele e prosseguiram a ensinar incontáveis outros estudantes em todo o mundo, deram-lhe talvez suas mais apreciadas satisfações pessoais. Dentre aqueles descendentes intelectuais, muitos se tornaram seus amigos pessoais. Eu sei também que algumas de suas mais profundas tristezas vieram quando estudantes que ele prezava faleceram; Eu acho que Fred nunca se conformou com a morte de Charlie Ferster. Notáveis entre os estudantes que ele valorizava, estavam aqueles do Brasil, onde ele, Gil Sherman e um pequeno grupo de estudantes brasileiros colocaram a Psicologia em novo rumo, um rumo que permanece florescendo até hoje, e que tem se espalhado internacionalmente desde então.

No entanto, apesar desses e outros sucessos, o que ele percebeu como sua falha em promover o PSI efetivamente deixou-o amargurado. Por favor, não me compreendam mal aqui; eu não estou dizendo que Fred era um homem amargo. Ele não era. Ele apreciava todos os aspectos positivos de sua vida, aqueles que acabei de resumir e muitos outros que não mencionei - em particular, Frances e seus filhos, John e Anne. Mas ele era claramente amargo com o PSI. Ele expressava sua amargura, 
entretanto, com humor auto-depreciativo e engraçado, e ao fazê-lo dessa forma, continua a nos ensinar. Isso é o que eu realmente quero enfatizar. Em suas últimas apresentações ele não se desculpou esbravejando contra um ambiente hostil, ou acusando outros de estupidez, desonestidade, incompetência ou malevolência. Sua amargura era claramente dirigida a si próprio. Claramente também, entretanto, mesmo em sua amargura, ele continuava a ensinar. $\mathrm{O}$ mundo é o que é, ele nos diz, e quando ele propôs sua solução para os problemas básicos da educação, ele falhou em levar em consideração as fontes de pressões, tanto de reforçamento como coercitivas, sobre as pessoas.

Seu propósito naquelas últimas conferências não era o de queixar-se, acusar, ou justificar-se. Seu propósito, como em tudo que ele fez, era o de ensinar. A respeito do PSI, ele estava tentando dizer a todos nós que, além de prover soluções criativas para problemas do mundo, nós também temos que fornecer técnicas para ensinar ao resto do mundo que nós merecemos sua atenção, apesar das dificuldades que se enfrentaria se se tentasse instituir as mudanças que estamos recomendando. Sua filosofia básica de experimentação, "Independentemente de como os dados se mostram, o sujeito está sempre certo", aplica-se também à educação. O estudante está sempre certo, e falhas dos estudantes em atingir as expectativas do professor requerem que os professores mudem seu próprio comportamento. Similarmente, em nossas interações com o mundo fora do laboratório, se o mundo falha em responder positivamente aos nossos ensinamentos baseados em dados, então temos que descobrir meios mais efetivos de apresentar esses ensinamentos.
O que me ocorreu, das últimas apresentações de Fred, foi a consciência de que as pessoas no mundo em geral, como os sujeitos no laboratório mais restrito, e como estudantes na sala de aula convencional, estão sempre certas, mesmo quando ignoram dados que nós achamos convincentes, e quando falham em adotar as sugestôes que fizemos com base nesses dados. Com respeito ao PSI, que recebeu apoio positivo por mais estudos publicados do que qualquer outro método de ensino jamais alcançou, o problema é basicamente o mesmo que em outros casos, quando o mundo falha em agir no que pareceria ser seus próprios melhores interesses. Nós vemos isso todo o tempo: por exemplo, todos concordam que fontes alternativas de energia são desejáveis; petróleo e gás vão acabar em um futuro previsível. Petróleo e gás, entretanto, são ainda as formas de energia mais baratas, e requerem menos inovação em métodos de produção e distribuição. O mesmo é verdadeiro com a educação. GSI, realizado por instrutores individuais lecionando para grandes grupos, é o menos dispendioso, e requer menos inovação no treino de professores e na estrutura do currículo. Ainda pior, diferentemente da situação no que diz respeito à energia, não há, desafortunadamente, nenhum fim previsível para o suprimento de palestrantes.

Fred Keller veio a se conscientizar claramente de que, para ter o PSI adotado, vai ser necessário mais do que criatividade intelectual em metodologia educacional. Quando simplesmente selecionamos como estudantes aqueles que não requerem quaisquer técnicas em particular de forma a aprender estudandes que vão aprender independentemente de quão ineficaz seja o sistema de instrução ao qual forem expostos - não podemos 
reivindicar que os tenhamos instruído. Esse fato, entretanto, não é suficiente para engendrar qualquer desejo de mudança no sistema. Os responsáveis pelo sistema olham para si próprios e para todas as pessoas de destaque que passaram pelo seu sistema, e concluem: "Ele funciona."

Bastante ironicamente, entre nós aqui, entre nós que, na tradição Oriental, reverenciamos Fred Keller como nosso Professor, quantos de nós ele ensinou via PSI? A despeito do GSI ao qual fomos expostos, nós fomos afortunados ao encontrar Fred; nós aprendemos com o que ele fez. Muitos outros são considerados grandes professores por muito menos. Nós aprendemos não com o que eles fizeram, mas das fontes às quais eles nos encaminharam; eles arranjaram para que chegássemos a essas fontes e aprendêssemos delas por quaisquer métodos que nós descobrimos que funcionavam para nós. $\mathrm{O}$ fato de que nem todos os estudantes foram bem sucedidos na aprendizagem, como fomos, apesar do sistema, é atribuído não a fracassos do sistema, mas a falhas internas daqueles estudantes desafortunados, a deficiências resultantes de falhas presumivelmente incontornáveis, como insuficiência de bases, Quocientes de Inteligência baixos, famílias descuidadas, e por aí afora.

A instituição de qualquer novo sistema, então, quer lidando com recursos energéticos, cuidados com a saúde, abuso de drogas, terrorismo, desigualdade econômica, ou qualquer problema cultural ou de dimensão comunitária, clama não apenas por competência criativa em uma área de interesse em particular. Os problemas aqui requerem algo mais do que habilidade analíticocomportamental em influenciar a conduta de indivíduos específicos. Para mudar práticas que as pessoas mantêm porque no momento elas são economicamente vantajosas, ou porque são simples de conduzir, ou porque se apoiam na tradição, é necessário influenciar grandes grupos de pessoas, sem se preocupar com membros específicos de um grupo.

Influenciar grandes grupos não é onde a Análise do Comportamento tem feito seu maior progresso teórico ou aplicado. De fato, nosso Táticas de Pesquisa Científica (Sidman, 1960) tomou quase como sua característica definidora a ênfase no comportamento do indivíduo — um cliente ou sujeito de cada vez. Nesse sentido, ela tem sido mais como a prática clínica da medicina, do que o tipo de análise estatística que caracteriza a ciência da Epidemiologia. A medicina clínica, como a análise do comportamento, tem de fato feito considerável progresso no alívio do sofrimento dos indivíduos que a procuram, mas deve-se reconhecer que os grandes avanços da saúde pública não têm vindo do tratamento de pessoas doentes. Ao contrário, devemos nossos crescentes tempo de vida e libertação de doenças a aplicações da ciência e da engenharia tecnológica em dimensões populacionais: por exemplo, as ciências e técnicas da bacteriologia aplicada, como na sanitização; virologia, como no controle dos vírus por meio de vacinação; engenharia sanitária, como nos esgotos modernos, e em coleta e tratamento de lixo e dejetos; purificação de comida e água, como na descontaminação e dessalinização; e coisas assim. O sistema PSI de instrução é uma contribuição da análise do comportamento que tem o potencial, como medidas de saúde pública de sucesso, de exercer efeitos de amplitude populacional, mas a análise do comportamento ainda não desenvolveu métodos para ganhar aceitação seja pelo empreendimento educacional, seja pelo público geral. 
O mesmo tem sido verdadeiro para outras contribuições analítico-comportamentais para a educação, como a instrução programada. Exceto por algumas poucas vozes isoladas clamando por extensões da análise do comportamento aos grupos sociais, e as tentativas recentes, mas ainda largamente desconhecidas, de desenvolver e aplicar o conceito teórico de metacontingência, a Análise do Comportamento não se dedicou ao problema de como ganhar aceitação profissional e da comunidade para suas contribuições potenciais para o bem estar geral.

Fred Keller nunca teve medo de examinar as críticas à ciência que ele ajudou a fundar. Quando eu era estudante, ele uma vez me deixou estupefato divagando alto sobre nossa compreensão do conceito básico de reforçamento. Ainda que ele não tivesse qualquer dado, ele achava que tinha observado, em sua vida diária, um fenômeno curioso. Parecia a ele que um reforço positivo dispensado apenas raramente por um pai que era usualmente desleixado ou negativo tinha um efeito maior sobre a criança do que muitos reforços dispensados por um pai que era usualmente dedicado e positivo. Aquela observação ficou em mim por todos esses anos, talvez porque penso que eu tenha observado a mesma coisa. Talvez não saibamos tudo que pensamos saber. Mas então, eu posso lembrar $\mathrm{da}$ resposta de Fred às primeiras iniciativas da análise comportamental aplicada; ele estava fascinado por mostrar a efetividade da aplicação, mas repudiava as afirmaçôes que alguns entusiastas precoces estavam fazendo sobre a generalidade do salto da pesquisa com não humanos para aplicações com humanos. Quando aquelas afirmaçôes se mostraram em grande medida corretas, ele ficou, claro, encantado, mas nunca teve medo de questionar as extensões da pesquisa básica que considerava prematuras ou extravagantes. E em suas contribuiçôes finais, ele não teve medo de procurar as razões pelas quais suas próprias contribuiçôes falharam em se tornar amplamente aceitas. Isso era o que ele estava nos dizendo, com seu humor e auto-admoestação gentis, em suas comunicaçôes finais. Nós, como professores, devemos procurar em nós mesmos as falhas para ensinar de forma bem sucedida. Ele não estava desistindo do PSI. Ele estava nos dizendo que nós tínhamos que dar atenção para variáveis que ele tinha ignorado, e de acordo com isso, mudar nossa técnica de ensino.

A lição final, então, que eu aprendi de Fred Keller, foi questionar a metodologia básica de nossas tentativas de realizar mudança comportamental em larga escala. Ele nunca forneceu a resposta a essa questão; ele nunca nos disse que mudanças fazer. Seu método de ensino nunca foi o de dizer aos estudantes o que fazer, mas ao contrário, prepará-los para a busca por mudanças efetivas em seu próprio comportamento. Ele não exagerava nas dicas, nem provia reforçamentos de qualquer jeito. Somente quando ele via estudantes abordando o comportamento de forma promissora de se mostrar produtiva, é que os reforçadores derramavam como vinho raro. Ele era um mestre em modelagem, mesmo quando não conhecia a forma exata do comportamento que procurava. Minha escolha pessoal com base naquelas últimas tentativas de gerar e modelar comportamento que ajudaria a avançar o PSI foi questionar a relevância de nossa metodologia de pesquisa básica ao tentar influenciar comportamento em larga escala, quando o que importa não é se um indivíduo em particular mudou seu comportamento mas se suficientes pessoas o fizeram, de forma a trazer melhoras ao bem estar geral. 
Isso não é abandono de nossa tradicional ênfase no indivíduo; essa ênfase tem sido bem sucedida demais para ser descartada apenas por não ter sido bem sucedida em resolver todos os problemas. É simplesmente uma constatação de que nem todos os problemas são suscetíveis aos mesmos tipos de soluçōes. Para fazer as contribuições de que nossa ciência é capaz, a análise do comportamento terá que usar métodos de generalidade mais ampla, no sentido de afetar muitas pessoas ao mesmo tempo - ou em curto tempo, sem estarmos necessariamente preocupados com quaisquer membros específicos da população relevante.

Eu gostaria de ter chegado a essa conclusão enquanto Fred ainda estava conosco. O reforçamento generalizado que ele provia era tão valioso para mim que se tornou uma necessidade, e hoje eu sinto saudades dele. $\mathrm{Na}$ verdade, eu lembro de um dos últimos reforçadores poderosos que ele me dispensou. Foi quando ele me disse que estava fazendo uma leitura completa do meu livro Coerção e suas conseqüências (Sidman, 2000) para poder apresentá-lo para discussão no clube do livro do qual ele era membro, junto a vários vizinhos.

Eu próprio, entretanto, estou atingindo o estágio em que estou provavelmente fazendo minhas próprias observações quase finais - sou certamente o mais velho dos estudantes sobreviventes de Fred; talvez eu seja mesmo o mais velho. Apenas Jim Dinsmoor, se não nos tivesse abandonado tão recentemente, poderia ter feito essa proclamação. Jim e eu tínhamos sido programados para iniciar a Homenagem a Keller, e ele teria tido muitas coisas relevantes e valiosas a dizer. Mas agora que eu sou possivelmente o mais velho da família estendida de Keller, não estou certo de que Fred poderia ainda modelar comportamento útil em mim. Muitos de vocês aqui, entretanto, têm tempo suficiente para levar a análise do comportamento ao próximo nível, para adicionar à suas aplicações clínicas individuais técnicas análogas àquelas das profissões de saúde pública. Espero ter ainda anos suficientes de vida para ver isso ocorrendo, e talvez ser capaz de prover algum reforço condicionado generalizado para aqueles, dentre vocês, que se moverem nessa direção.

\section{REFERÊNCIAS}

Breland, K., \& Breland, M. (1961). The misbehavior of organisms. American Psychologist, 16, 681-684.

Keller, F. S. (1941). Light aversion in the white rat. The Psychological Record, 4, 235-250.

Keller, F. S. (1943). Studies in International Morse code. 1. A new method of teaching code reception. Iournal of Applied Psychology, 27, 407-415.

Keller, F. S. (1985). Lightning strikes twice. Teaching of Psychology, 12, 4-8.

Keller, F. S., \& Schoenfeld, W. N. (1949). The psychology curriculum at Columbia College. Americal Psychologist, 4, 165-172.

Pryor, K. (1999). Don't shoot the dog. Revised edition. New York: Bantam.

Sidman, M. (1960). Tactics of sientific research: evaluating experimental data in Psychology. New York: Basic Books. Reprinted (1988). Boston: Authors Cooperative.

Sidman, M. (1989). Coercion and its fallout. Boston: Authors Cooperative. (Revised Edition, 2000).

Wilson, M. P., \& Keller, F. S. (1953). On the selective reinforcement of spaced responding. Journal of Comparative and Physiological Psychology, 46, 190-193.

Artigo convidado Tradução recebida em 31 de outubro de 2006 


\title{
PROGRAMA DE PÓS-GRADUAÇÃO EM NEUROCIÊNCIAS E COMPORTAMENTO
}

\author{
Universidade de São Paulo \\ Cursos: MESTRADO E DOUTORADO \\ Área de concentração \\ Neurociências e Comportamento \\ Linhas de Pesquisa \\ Sistemas Sensoriais e Motores \\ Desenvolvimento e Plasticidade \\ Neurotransmissores e Comportamento \\ Percepção e Expressão Humana \\ COORDENADORA: MARIA TERESA ARAÚJO SILVA
}

DOCENTES:

André Fábio Kohn

Antonia Gladys Nasello

César Ades

Clarice Gorenstein

Dora Selma Fix Ventura

Elisabeth Spinelli de Oliveira

Gerson Chadi

Gilberto Fernando Xavier

Helenice de Souza Spinosa

Hilton Ferreira Japyassú

João Palermo Netto

José Lino O. Bueno

Klaus Bruno Tiedemann

Koichi Sameshima
Luciano Freitas Felício Luiz Eduardo Ribeiro do Valle

Luiz S. Menna-Barreto

Luiz Roberto G. Britto

Maria Helena L. Hunziker Maria Inês Nogueira

Maria Martha Bernardi

Maria Teresa Araújo Silva

Newton Sabino Canteras

Nielsy Helena P. Bergamasco

Ronald Clive Ranvaud

Sérgio L. D. Cravo

Taki Athanássios Cordás

Informações adicionais na página da internet: www.ip.usp.br/posp/neclinst_depto_nec_posg.htm 